\title{
Response of Semi-solid Sn-15 Pct Pb to Rapid Shear-Rate Changes
}

\author{
T.Y. LIU, H.V. ATKINSON, P.J. WARD, and D.H. KIRKWOOD
}

\begin{abstract}
Semisolid metal alloys, used in thixoforming, are thixotropic. The slurry viscosity is shear-rate- and time dependent provided the microstructure in the semisolid state is nondendritic and consists of solid spheroids surrounded by liquid. Thixoforming takes less than 1 second, during which time the structure of the material breaks down. This breakdown can be studied by viscometry, using rapid data-collection rates, by imposing rapid increases in shear rate on the slurry. An initial rapid ( $<1$ second) structural breakdown during a shear-rate jump is followed by a more gradual decrease in viscosity, lasting several minutes. The slurry breaks down more rapidly with a higher final shear rate, but the first breakdown time is independent of the initial shear rate. The reverse is found with the shear-rate drops: recovery times increase with increasing final shear rate. Again, this time is independent of the starting shear rate. The shear stress and viscosity during initial breakdown and initial recovery can be described by single exponential equations. Build-up processes were examined by performing jumps after allowing the slurry to rest at a zero shear rate for different times. The increase in peak stress with rest time reflects the evolving degree of particle agglomeration. Microstructural examination confirms this phenomenon.
\end{abstract}

\section{INTRODUCTION}

VIGOROUS agitation of metal alloys during solidification can produce near-spheroidal solid particles suspended in the liquid matrix. These interacting solid particles, held together by microscopic bonds (i.e., metallic bonds formed by the collision of solid particles) when the alloy is left at rest, enable the material to be handled like a solid. When a shear stress is imposed, the bonds between the particles are broken down and the material flows in a laminar way. This behavior, known as thixotropy, has been shown extensively in semisolid metal slurries. ${ }^{[1-9]}$ Thixotropy is defined, according to the British Standards Institution, as the "decrease in viscosity under stress, followed by gradual recovery when the stress is removed." This effect is time dependent. Figure 1 shows a schematic diagram of the change in viscosity with time following changes in shear rate. Semisolid metal processing (or thixoforming), where the nondendritic metal slug is heated to its semisolid temperature before forming it into a die, exploits this behavior and, hence, lower power/energy is needed compared to solid forging. Compared with the turbulent flow in die casting of fully liquid metal the flow is laminar and there is less shrinkage porosity and/or gas entrapment. Thixoforming is a viable industrial process. ${ }^{[10-14]}$ However, the rheological behavior of the alloy slurries requires further investigation. In particular, the slurry undergoes a sudden increase in shear rate from rest to $100 \mathrm{~s}^{-1}$ or more as it enters the die. This change takes place in less than 1 second. Hence, measuring the

T.Y. LIU, Ph.D. Student, and P.J. WARD, Postdoctoral Research Fellow, are formerly with the Department of Engineering Materials, University of Sheffield. H.V. ATKINSON, formerly Reader with the Department of Engineering Materials, University of Sheffield, is Professor, Department of Engineering, University of Leicester, Leicester, LE1 7RH United Kingdom. Contact e-mail: hvatkinson@aol.com D.H. KIRKWOOD, Honorary Senior Lecturer, is with the Department of Engineering Materials, University of Sheffield, Sheffield, S1 3JD United Kingdom.

Manuscript submitted April 15, 2002. rheological response under rapid changes in shear rate is critical to the development of modeling of die filling and successful die design. ${ }^{[15,16]}$

The majority of previous work ${ }^{[1-5]}$ has centered on measuring the steady-state viscosity $(\eta)$ of a $\operatorname{Sn} 15$ pct $\mathrm{Pb}$ semisolid metal slurry achieved over a period of time after a change in shear rate $(\hat{\gamma})$. The microstructural characteristics of the $\mathrm{Sn} 15$ pct $\mathrm{Pb}$ alloy are known to be similar to those of the thixoformable aluminum alloys used in the manufacturing industry. An additional advantage of using the Sn15 $\mathrm{pct} \mathrm{Pb}$ alloy for viscometry experiments is its low melting temperature and wide semisolid temperature range.

The results for steady-state viscosity $\left(\eta_{e}\right)$ from previous works, ${ }^{[3,6,7]}$ together with results obtained from the authors' earlier work, ${ }^{[17]}$ have been fitted to the Cross equation: ${ }^{[18]}$

$$
\frac{\eta_{e}-\eta_{\infty}}{\eta_{0}-\eta_{\infty}}=\frac{1}{1+k \dot{\gamma}^{n}}
$$

where $k$ and $n$ are material constants, and the subscripts o and $\infty$ represent the viscosity at a zero shear rate and viscosity at an infinite shear rate, respectively.

Figure 2 shows the steady-state viscosities plotted against shear rates from several studies using Eq. [1]. The equation describes the response to shear rate of a pseudoplastic fluid, i.e., one with no time dependence. A thixotropic alloy exhibits a delayed response to shear rate, so that, for instance. after a rapid rise in shear rate, the viscosity is initially above the equilibrium value and decays toward that value. This decay is described by a characteristic time (relaxation time ${ }^{[19]}$ ), which is technologically important if it is of the same order of magnitude as the injection time used in thixoforming. The study given in the following text shows that the steady-state results (usually obtained after 1 hour of constant shearing by fitting Eq. [1]), shown in Figure 2, are not appropriate for describing the rheological behavior of the metal slurry during thixoforming, because these two times are indeed not comparable.

Kumar, ${ }^{[20]}$ Quaak, ${ }^{[21]}$ and Peng and Wang ${ }^{[22]}$ investigated 


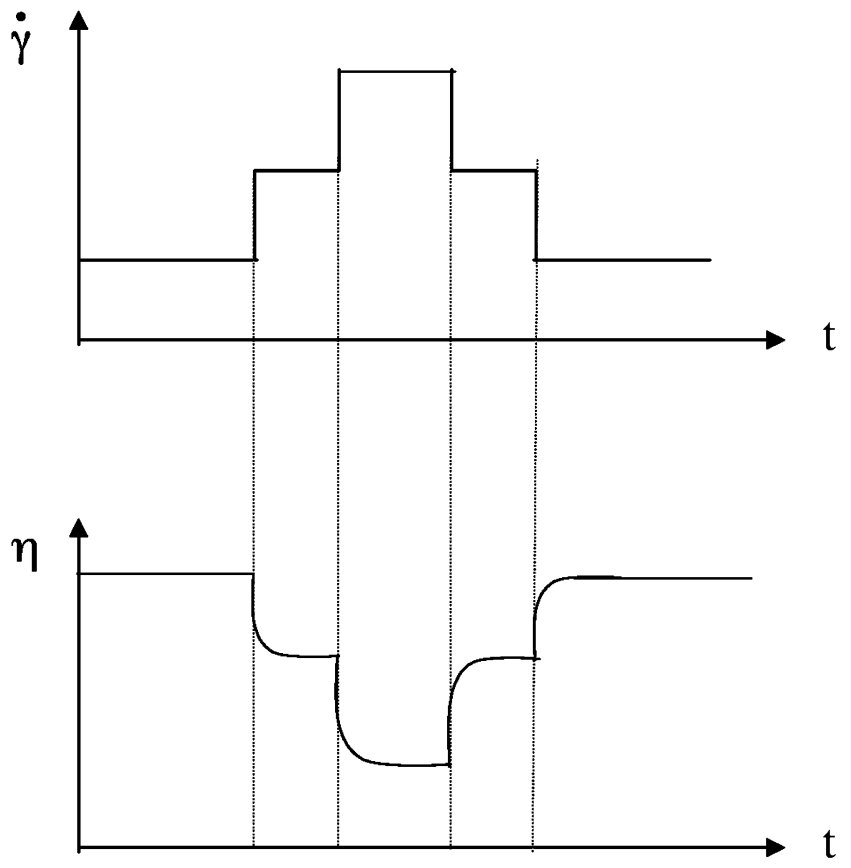

Fig. 1-Schematic diagram showing the changes of viscosity with time under shear rate changes for a thixotropic material.

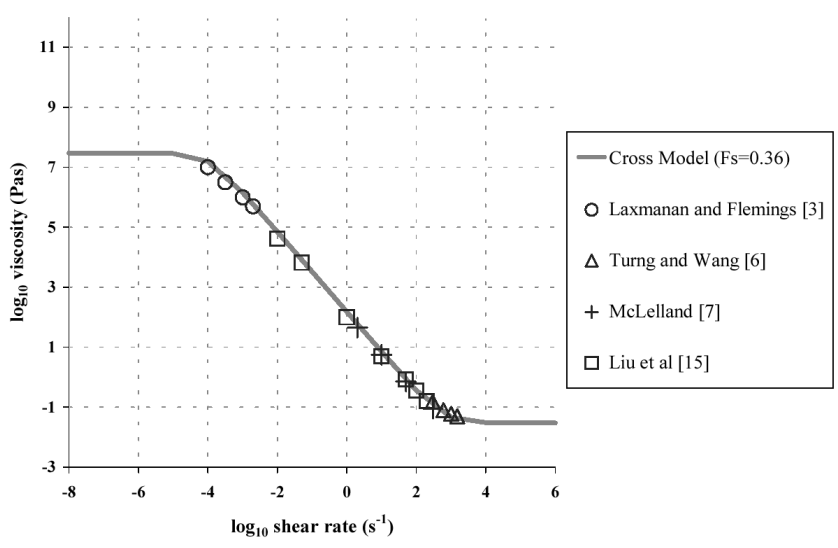

Fig. 2-Apparent steady-state viscosities at different shear rates fitted to the cross model for $\mathrm{Sn} 15 \mathrm{pct} \mathrm{Pb}$ alloys $\left(F_{s}=0.36\right)$ from several studies.

the transient behavior during a sudden change in shear rate. Two relaxation times were quantified: (1) breakdown time and (2) buildup time. The breakdown time is the characteristic time for the slurry to achieve its steady-state condition after a shear-rate change from a lower value to a higher value, while the buildup time is for a change from a higher shear rate to a lower shear rate. These workers found that the times for breakdown are faster than those for buildup. This would be expected, as the breaking up of "bonds" between spheroidal solid particles in agglomerates during shear-rate jumps in the slurry is likely to be easier than the formation of bonds during shear-rate drops. Bond formation will require not only collision between particles but also, once a permanent contact point is formed, the further development of the "neck" between the particles, a time-dependent process. Quaak ${ }^{[21]}$ proposes two characteristic times to describe a shear rate. He suggests that during the shear-rate change, the slurry undergoes an initial rapid breakdown/

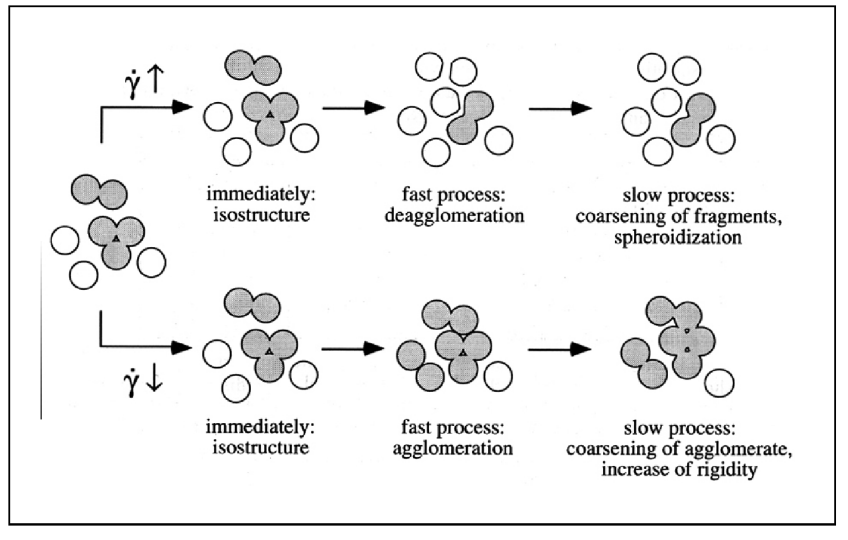

Fig. 3-Schematic model describing the fast and slow processes in a semisolid material's structure after shear rate up and down jumps (taken from Ref. 21).

buildup followed by a more gradual breakdown/buildup. This can be described by a double exponential expression. Quaak gives Figure 3 as the microstructural basis for the double exponential term used. Immediately after a change in shear rate, the structure remains the same ("iso-structure"). This is followed by a very fast process, viz., breakdown (after a jump) or buildup (after a drop) of agglomerates. There is then a slow process, associated with diffusion, giving coarsening and spheroidization. So far, work carried out to study the initial rapid breakdown/buildup times in semisolid metal slurry have been limited. ${ }^{[20-23]}$ The work described here is concerned with the "very fast process" and uses data-collection rates faster than those previously achieved. Rapid breakdown/buildup times are investigated using a $\mathrm{Sn} 15$ pct $\mathrm{Pb}$ alloy, identifying the dependence on initial and final shear rates and relating the results to the microstructural changes.

\section{EXPERIMENTAL PROCEDURE}

The apparatus used for these experiments on the Sn15 pct $\mathrm{Pb}$ alloy is a Haake ME500 viscometer. This is a Searletype viscometer, where the inner cylinder is rotating and the shear stress and shear rate are measured from it (Figure 4). Shear rates were restricted to a maximum of $200 \mathrm{~s}^{-1}$. At higher shear rates than this, the inner rotor was displaced off-center, resulting in errors in the results. A data-collection card ( $\sim 1 \mathrm{kHz}$ capture rate) is used during the rapid increase in shear rate. This collection rate is significantly faster than that used by other workers $(200 \mathrm{~Hz}$ in Reference $20,9 \mathrm{~Hz}$ in Reference 21, and $200 \mathrm{~Hz}$ in Reference 22). This fast collection rate enables the capture of the very fast process, as proposed by Quaak, ${ }^{[21]}$ during the shear-rate change. The semisolid slurries are generated by stirring the Sn 15 pct $\mathrm{Pb}$ alloy while cooling from above the liquidus point to the required semisolid temperature (i.e., fraction of solid). The temperature accuracy was measured by comparing the difference between the temperature on the inner surface of the cup with that from the furnace controller. The accuracy was found to be within $1{ }^{\circ} \mathrm{C}$. In addition, temperatures were stable to within $1{ }^{\circ} \mathrm{C}$ over the course of the experiments, in agreement with earlier work. ${ }^{[24]}$ Stirring is continued at the required fraction of solid until an apparent steady state is 


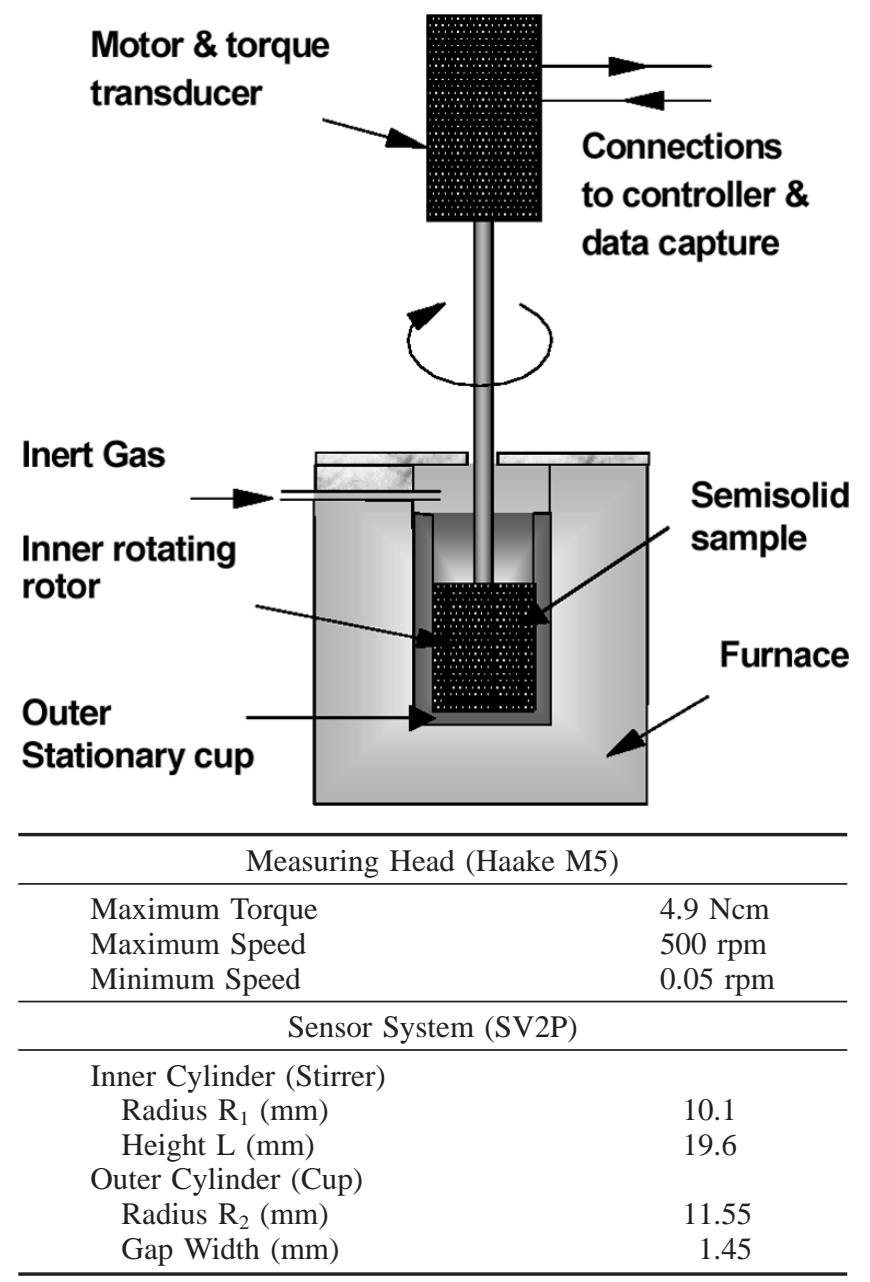

Fig. 4-Schematic diagram of a Searle-type viscometer used in this experiment.

obtained. The stirring breaks up the dendritic structures normally formed during solidification, resulting in solid spheroids in a liquid matrix. The specimen is protected from oxidation by passing an inert gas (nitrogen or argon) over the material. Shear-rate jumps were conducted for several different rest times and initial and final shear rates. The samples were extracted from the annular gap using a thin copper rod and were quenched rapidly in water. The metallography samples were then prepared in the usual manner.

\section{SOURCES OF ERROR}

Three possible sources of error in the shear-stress curves were considered:

(1) effects of momentum diffusion through the slurry,

(2) inertia effects of the measuring head, and

(3) electronic switching during the step change in shear rate.

When the inner cylinder is accelerated, a finite time is required for the momentum to propagate across the gap between the cylinders. An approximate relation, based on the momentum-diffusion equation between two planar surfaces, allows the calculation of this time: ${ }^{[25]}$

$$
t=\frac{0.45 x^{2}}{v}
$$

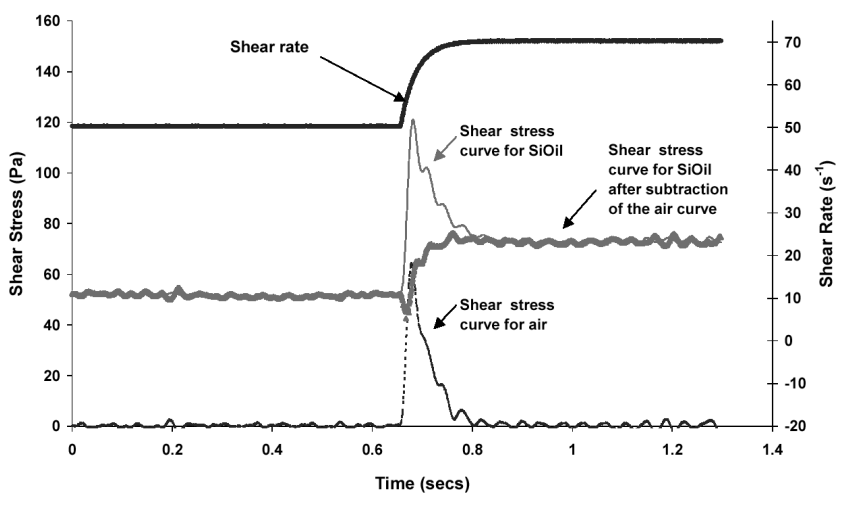

Fig. 5-Effect of inertia from the measuring head of the viscometer (shear rate jump 50 to $70 \mathrm{~s}^{-1}$ in 1 Pas Newtonian oil (SiOil)).

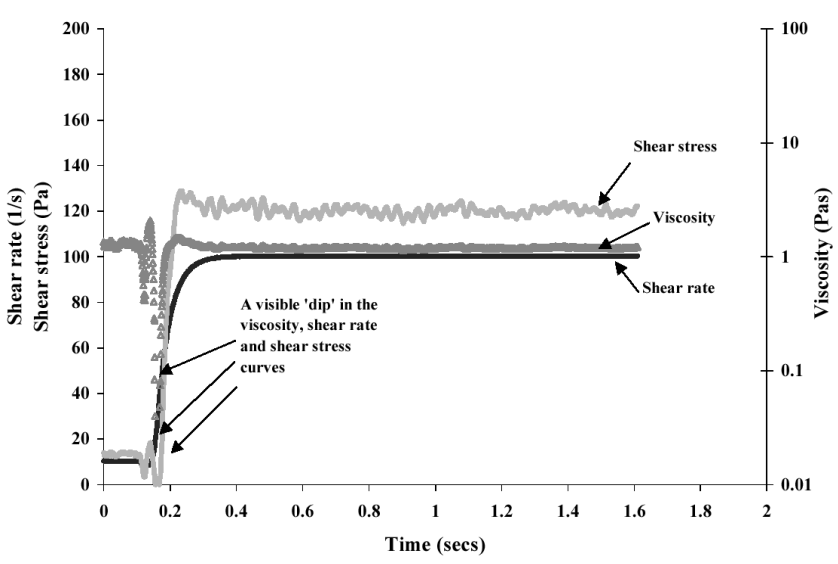

Fig. 6-Shear rate jump in 1 Pas Newtonian oil $\left(10\right.$ to $\left.100 \mathrm{~s}^{-1}\right)$. The "dip" effect is seen on the shear rate, shear stress, and viscosity curves.

where $x$ is the gap width and $v$ is the kinematic viscosity of the fluid.

For a Newtonian fluid of viscosity 0.001 Pas (e.g., water), this equation gives a diffusion time of 1 second for the gap used in this study $(1.45 \mathrm{~mm})$. The time for a 1 Pas fluid of the same density would, thus, be $1 \mathrm{~ms}$. In the present study of $\mathrm{Sn} 15$ pct $\mathrm{Pb}$, it was concluded that the momentum diffusion would not affect the experimental results due to the high viscosities in the $\mathrm{Sn} 15$ pct $\mathrm{Pb}$ alloy before the shear-rate jumps.

The effect of inertia was investigated by running shearrate jumps in air. Figure 5 shows the effect of the inertia of the measuring head. Shear-rate jumps in air and in 1 Pas Newtonian oil produce similar patterns. By subtracting these two curves, it can be seen that the peak produced in the oil has disappeared, to give a curve as for a Newtonian fluid. The peak obtained earlier (i.e., before subtraction) can be attributed to the inertia of the measuring head.

In all the shear-rate jumps conducted from an initial shear rate above zero, a "dip" was observed in both the shear-rate and shear-stress curves when the initial shear rate was less than $30 \mathrm{~s}^{-1}$. The cause of this dip was attributed to the electronic switching system in the viscometer's controller, after a series of tests in air showed the same dip effect at initial shear rates less than $30 \mathrm{~s}^{-1}$. Figure 6 shows the shearstress and viscosity behavior of a Newtonian oil (of 1 Pas viscosity) during a step change in shear rate from 10 to 


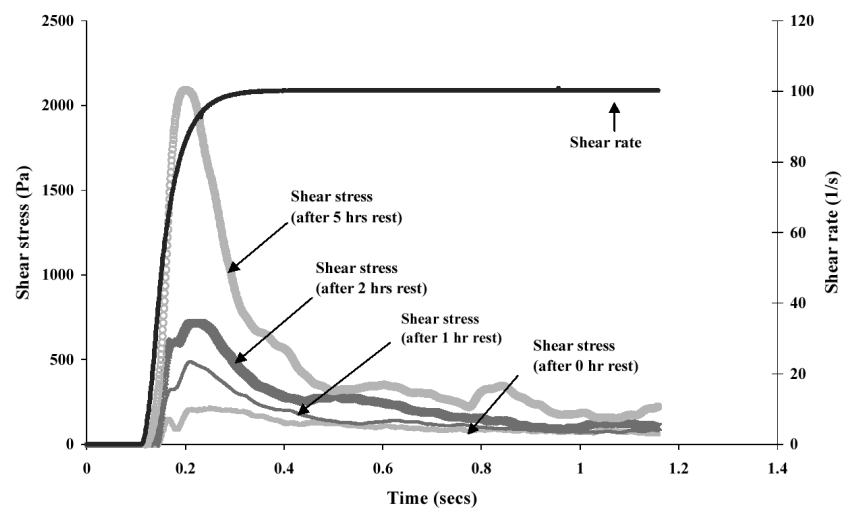

Fig. 7-Shear rate jumps from 0 to $100 \mathrm{~s}^{-1}$ after different rest times for $\mathrm{Sn} 15 \mathrm{pct} \mathrm{Pb}$ alloy at fraction solid 0.36.

$100 \mathrm{~s}^{-1}$. It can be seen that the shear stress increases with increasing shear rate, while the viscosity remains constant after the jump. However, the dip in the shear rate during the shear-rate jump has an effect on the recorded peak shear stress and peak stress viscosity. Henceforth, results for all the shear-rate jumps are examined after the shear rate has reached $\sim 90$ pct of its specified final shear rate.

\section{EXPERIMENTAL RESULTS}

Figure 7 shows the results of a shear-rate jump in Sn15 pct $\mathrm{Pb}$ from 0 to $100 \mathrm{~s}^{-1}$ after different rest times. The curves were corrected for instrument inertia as described in the preceding section. From the graph, it can be seen that with longer rest times, the initial stress (or the peak stress recorded) increases. An important point to note in this result is that the graph showed a continued decrease in shear stress even after the shear rate had reached its specified value. This time-dependent behavior is characteristic of thixotropy and confirms that the Cross equation (Eq. [1]) is not appropriate for describing the rheological changes in the semisolid slurry after a shear-rate jump.

The descending portion of the shear-stress curve was then fitted to a single exponential rate equation proposed by Moore. ${ }^{[26]}$ The period examined is the 1 second after 90 pct of the specified final shear rate was achieved, and the equation proposed by Moore is

$$
\frac{\sigma-\sigma_{f}}{\sigma_{i}-\sigma_{f}}=\frac{\eta-\eta_{f}}{\eta_{i}-\eta_{f}}=e^{-t / \tau}
$$

where $\sigma_{i}$ and $\sigma_{f}$ are the initial and final shear stresses used in the calculation of the exponential decay curve, respectively, and $\sigma$ is the instantaneous shear stresses. The terms $\eta_{i}, \eta_{f}$, and $\eta$ are the corresponding viscosities, and $\tau$ is the breakdown (relaxation) time at time $(t)$.

Figure 8 shows that a good fit of the curve from the experimental results can be obtained by using this equation. The parameters calculated for a series of rest times from the fits to the experimental curves as in Figure 8 are shown in Table I. The peak-stress viscosity $\left(\eta_{p}\right)$ is shown to increase with rest time, while the breakdown time $(\tau)$ decreases with increasing rest time.

The aforementioned breakdown times are obtained from the data recorded using the fast data card $(\sim 1 \mathrm{kHz})$. Data is collected throughout the first second after the machine is

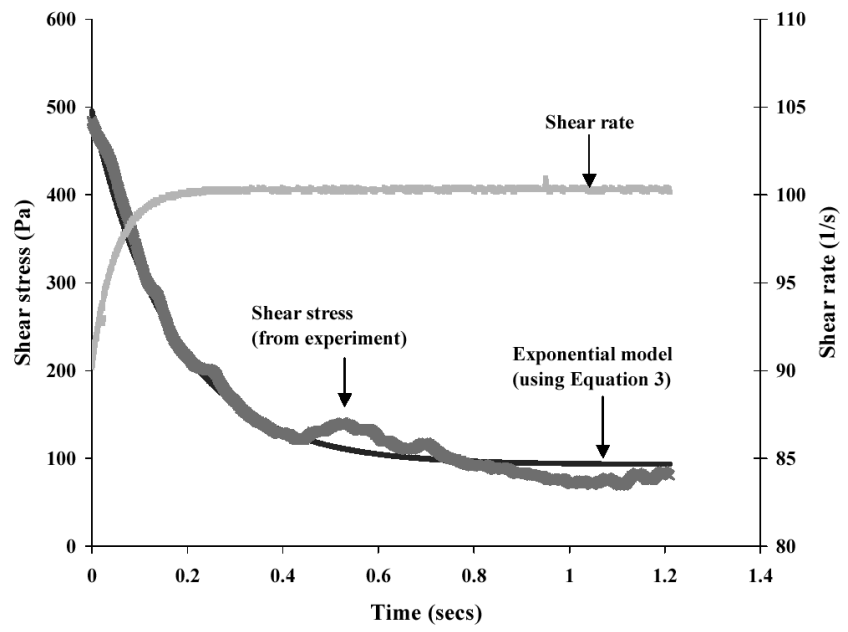

Fig. 8-Curve fitting for shear rate jump experiments on Sn15 pct $\mathrm{Pb}$ alloys $\left(F_{s}=0.36\right.$, rest time $=1 \mathrm{~h}$ ) from 0 to $100 \mathrm{~s}^{-1}$ (from Fig. 6) using Eq. [3].

Table I. Tabulation of Parameters Obtained from Shear Rate Jump Experiments on Sn15 Pct Pb Alloys (at $F_{s}=$ 0.36) under Different Rest Times

\begin{tabular}{|c|c|c|c|c|}
\hline Shear Rate Jumps $\left(\mathrm{s}^{-1}\right)$ & \multicolumn{4}{|c|}{0 to 100} \\
\hline Rest times (h) & 0 & 1 & 2 & 5 \\
\hline$\eta_{p}(\mathrm{Pas})^{*}$ & 2.1 & 5.4 & 8.0 & 23.0 \\
\hline$\eta_{s . s}(\mathrm{Pas})^{* *}$ & 0.8 & 0.8 & 1.2 & 2.0 \\
\hline$\tau(\mathrm{s}) \dagger$ & 0.18 & 0.16 & 0.15 & 0.12 \\
\hline
\end{tabular}

$*$ The errors are within 95 pct confidence limit $( \pm 0.5)$.

$* *$ The errors are within 95 pct confidence limit $( \pm 0.2)$.

$\uparrow$ The errors are within 95 pct confidence limit $( \pm 0.03)$.

instructed to make the shear-rate change. This does not reflect the complete shear-thinning behavior of the Sn15 pct $\mathrm{Pb}$ alloy. Therefore, it should be mentioned here that the value of $\eta_{\mathrm{s} \cdot \mathrm{s}}$ in Table I is the "first" steady-state viscosity (or pseudostate viscosity) after a shear-rate jump, and the breakdown time is known as the "first" breakdown (or relaxation) time.

Table II shows the calculated parameters (peak-stress viscosities, pseudostate viscosities, and breakdown times) for $\mathrm{Sn} 15$ pct $\mathrm{Pb}$ alloys at different rest times, for the different final shear rates specified. It is clear from the results that the breakdown times and peak-stress viscosity are influenced both by the final shear rate specified and the length of the rest time.

Table III shows the results for three different fractions of solid after similar shear-rate jumps and rest times (shearrate change from 0 to $50 \mathrm{~s}^{-1}$ and after 0 and 1 hours of rest time, respectively). Both the peak-stress and final viscosities increase with increasing fraction of solid, while the breakdown times remain almost the same. The viscosity values increase with increasing fraction of solid. However, the breakdown times show some discrepancies. At $F_{s}=0.36$ for a rest time of 0 hours, the breakdown time calculated is faster than that for the experiment done at $F_{s}=0.2$, but slower than that for the experiment carried out at $F_{s}=0.5$. For the same test at a rest time of 1 hour, the breakdown times are similar to each other. There is no apparent trend 
Table II. Tabulation of Parameters Obtained from Different Shear Rate Jump Experiments on Sn15 Pct Pb Alloys (at $\boldsymbol{F}_{s}=\mathbf{0 . 3 6}$ ) under Different Rest Times

\begin{tabular}{|c|c|c|c|c|c|c|c|c|c|c|c|}
\hline \multirow{2}{*}{$\frac{\text { Shear Rate Jumps }\left(\mathrm{s}^{-1}\right)}{\text { Rest times }(\mathrm{h})}$} & \multicolumn{4}{|c|}{0 to 50} & \multicolumn{4}{|c|}{0 to 100} & \multicolumn{3}{|c|}{0 to 200} \\
\hline & 0 & 1 & 2 & 5 & 0 & 1 & 2 & 5 & 0 & 1 & 2 \\
\hline$\eta_{p}(\mathrm{Pas})^{*}$ & 3.6 & 8.8 & 13.3 & 37.0 & 2.1 & 5.4 & 8.0 & 23.0 & 0.6 & 1.6 & 3.4 \\
\hline$\eta_{s . s}(\mathrm{Pas})^{* *}$ & 1.9 & 1.8 & 2.1 & 3.6 & 0.8 & 0.8 & 1.2 & 2 & 0.4 & 0.7 & 1.0 \\
\hline$\tau(\mathrm{s}) \dagger$ & 0.20 & 0.18 & 0.18 & 0.14 & 0.18 & 0.16 & 0.15 & 0.12 & 0.15 & 0.13 & 0.13 \\
\hline
\end{tabular}

*The errors are within 95 pct confidence limit $( \pm 0.5)$.

**The errors are within 95 pct confidence limit $( \pm 0.2)$.

$\dagger$ The errors are within 95 pct confidence limit $( \pm 0.03)$.

Table III. Tabulation of Parameters Obtained for Different Fraction Solids of Sn15 Pct Pb Alloys to a Final Shear Rate of $50 \mathrm{~s}^{-1}$

\begin{tabular}{|c|c|c|c|c|c|c|}
\hline \multirow{2}{*}{$\frac{\text { Shear Rate Jump }\left(0 \text { to } 50 \mathrm{~s}^{-1}\right)}{\text { Fraction Solid }\left(F_{s}\right)}$} & \multicolumn{3}{|c|}{ Rest Time of $0 \mathrm{~h}$} & \multicolumn{3}{|c|}{ Rest Time of $1 \mathrm{~h}$} \\
\hline & $\eta_{p}(\mathrm{Pas})^{*}$ & $\eta_{s . s}(\mathrm{Pas})^{* *}$ & $\tau(\mathrm{s}) \dagger$ & $\eta_{p}(\mathrm{Pas})^{*}$ & $\eta_{s . s}(\mathrm{Pas})^{* *}$ & $\tau(\mathrm{s}) \dagger$ \\
\hline 0.20 & 1.9 & 0.7 & 0.11 & 2.1 & 0.9 & 0.19 \\
\hline 0.36 & 3.6 & 1.9 & 0.20 & 8.8 & 1.8 & 0.18 \\
\hline 0.50 & 16.8 & 5.1 & 0.14 & 43.1 & 6.5 & 0.18 \\
\hline
\end{tabular}

*The errors are within 95 pct confidence limit $( \pm 0.5)$.

**The errors are within 95 pct confidence limit $( \pm 0.2)$.

$\dagger$ The errors are within 95 pct confidence limit $( \pm 0.03)$.
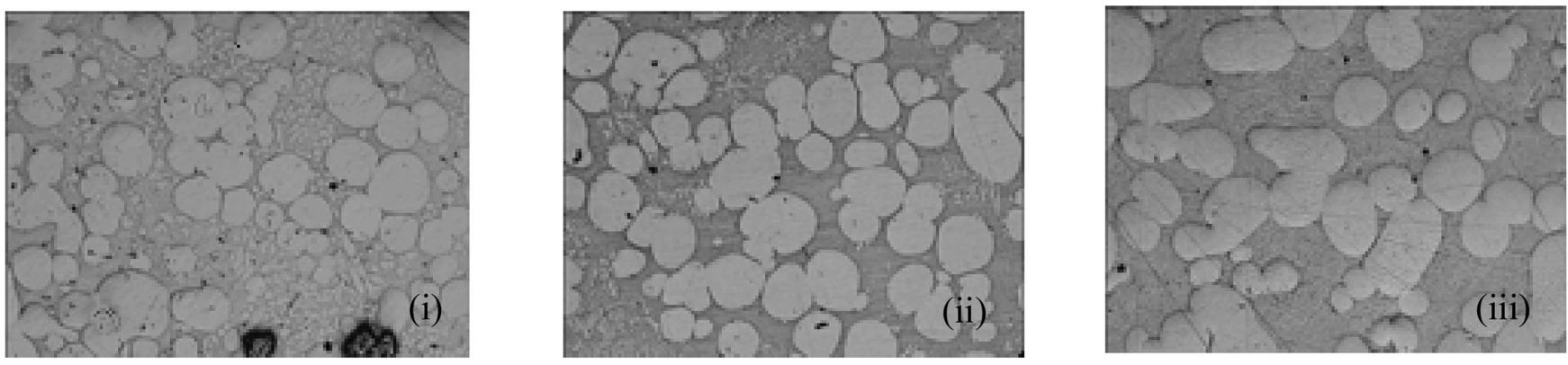

\section{$200 \mu \mathrm{m}$}

Fig. 9-Microstructures of $\operatorname{Sn} 15$ pct Pb alloy $\left(F_{s}=0.36\right)$ at various rest times: (i) $0 \mathrm{~h}$, (ii) $1 \mathrm{~h}$, and (iii) $2 \mathrm{~h}$.
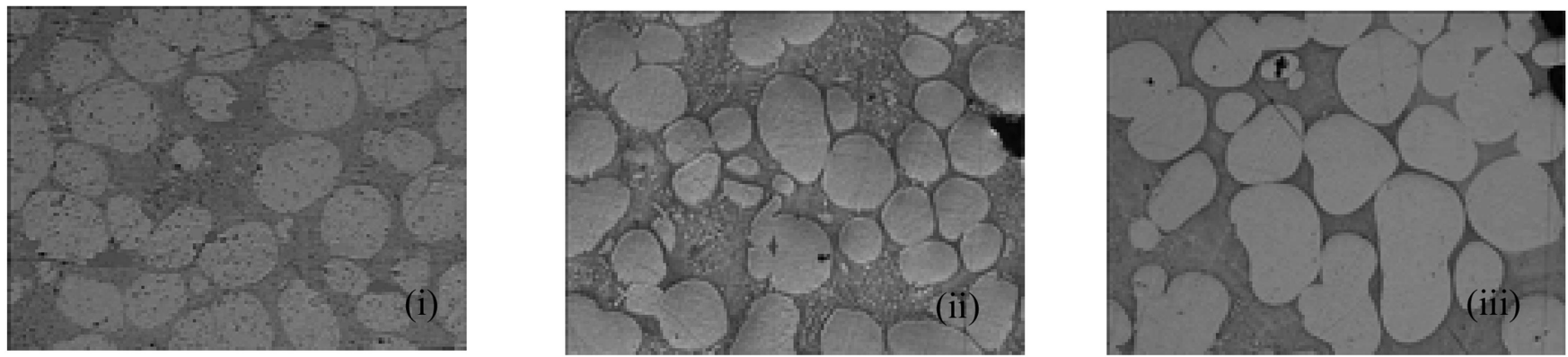

\section{$200 \mu \mathrm{m}$}

Fig. 10-Microstructures of $\operatorname{Sn} 15$ pct $\mathrm{Pb}$ alloy $\left(F_{s}=0.5\right)$ at various rest times: (i) $0 \mathrm{~h}$, (ii) $1 \mathrm{~h}$ and (iii) $2 \mathrm{~h}$.

that can be seen from the results here. However, both results at $F_{s}=0.2$ and 0.5 showed that the breakdown occurs more rapidly with a longer rest time (i.e., $\tau$ is shorter).

Figures 9 and 10 show the microstructures of Sn15 pct
$\mathrm{Pb}$ alloys under different rest times. In Figures 9 and 10, microstructural examination shows that increasing the rest time increases the solid-particle size. This increase would impede the movement of the particles upon an imposition 


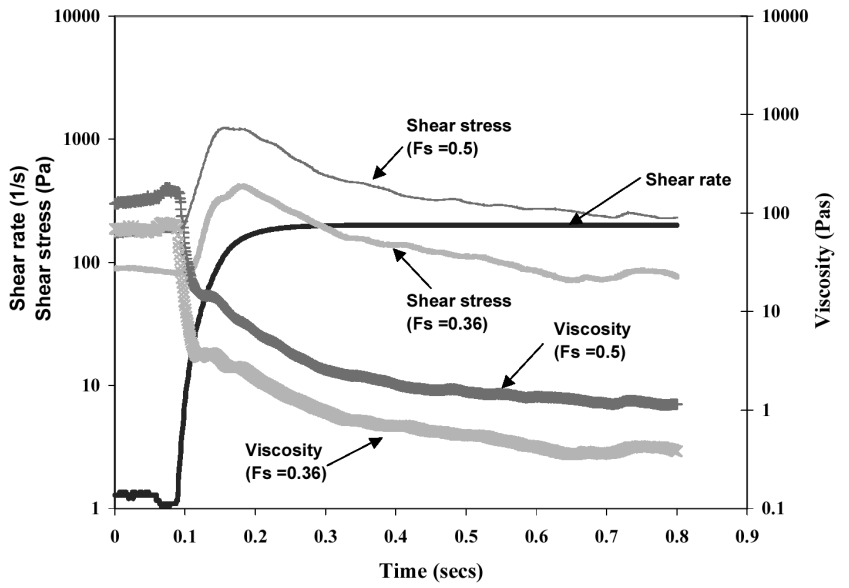

Fig. 11-Shear rate jumps ( 1 to $\left.200 \mathrm{~s}^{-1}\right)$ for $\mathrm{Sn} 15 \mathrm{pct} \mathrm{Pb}$ alloy $\left(F_{s}=0.5\right.$ and 0.36 )

of a shear-stress rate. The ease with which the particles are able to move past each other depends on the fraction of liquid medium present, the size of the particles, and their degree of agglomeration. This relates to the shear stress recorded during a sudden imposition of shear rate. For accurate measurements, the particle size must be less than onethird the size of the annular gap in the viscometer system. For the system used here, it was found that the largest particle size measured is less than one-third of the gap width. If "particle bridging" were to occur, i.e., large particles joining together to form a solid structure across the viscometer gap interfering with flow, this would affect the peak stress but not the decay portion of the curve after the peak, when flow is occurring.

From Figures 9 and 10, it can be seen that at longer rest times and higher fractions of solid, the solid particles are larger and more clustered, giving a higher value of peak stress with increasing rest time.

Figure 11 shows shear-rate jumps (from 1 to $200 \mathrm{~s}^{-1}$ ) for two different fractions of solid $\left(F_{s}=0.36\right.$ and 0.5$)$. It can be seen that the peak stress and viscosity encountered increase with increasing fraction of solid. The viscosity values for each fraction of solid at 1 and $200 \mathrm{~s}^{-1}$ correspond to those found during the steady-state experiments (Figure 2). This implies that the semisolid alloy has a constant structure (i.e., constant viscosity) before the shear-rate jump.

Following the curve-fitting procedure in the rest-time experiments, the breakdown times for the step-change experiments were obtained for a series of initial and final shear rates. Figure 12 shows six examples of the curve-fitting attempts (after the shear rate had reached $\sim 90$ pct of its final shear rate) at different $\dot{\gamma}_{i}$ and $\dot{\gamma}_{f}$ values, respectively, for both shear-rate jumps and drops.

Table IV lists the calculated parameters for the various shear-rate jumps for fractions of solid of 0.36 and 0.5 . From the table, it can be seen that the peak-stress viscosity encountered during the step change decreases with increasing initial shear rate. This can be attributed to the slurry being more "broken down" before the step change and, hence, a lower viscosity value is recorded. By comparing the viscosity values for the same initial shear rate, it was found that the viscosity values differ slightly from each other. The viscosity and breakdown-time values are found to be greater for a
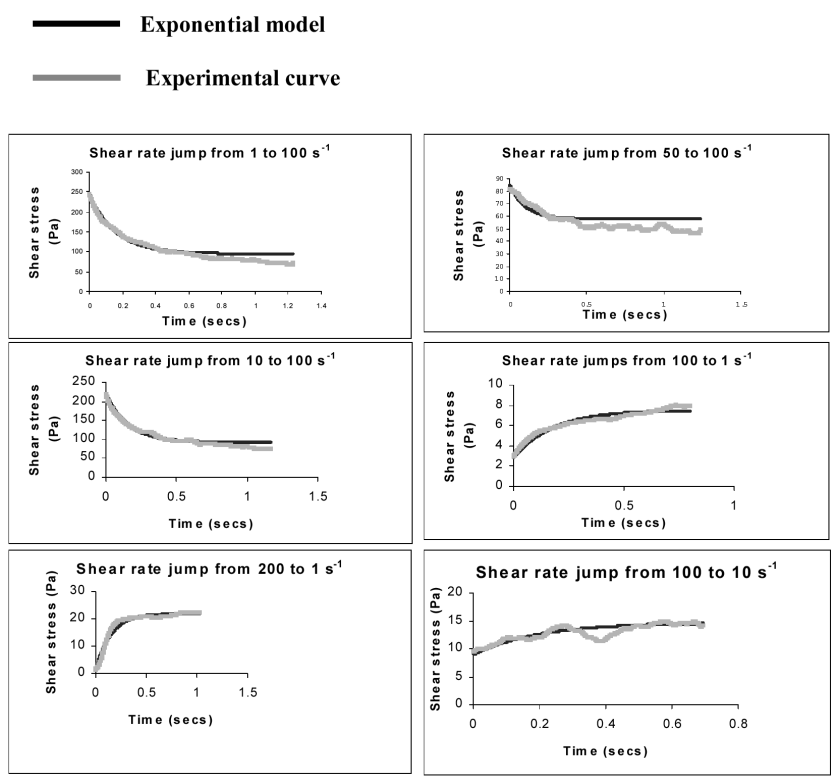

Fig. 12-Examples of curve fitting to various shear rate jumps up and jumps down experiments using Eq. [3].

fraction of solid of 0.5 , as expected from a more packed structure.

Figures 13 and 14 plot the parameters (breakdown times, peak stress, and pseudoviscosity) obtained for shear-ratejump experiments. From the graphs, it was found that the breakdown times do not differ greatly for the same final shear rate (Figure 13). On the other hand, the breakdown times decrease with increasing final shear rate (Figure 14). Figures 15 and 16 plot the same parameters for shear-ratedrop experiments. The results for the step change to a lower shear rate showed similar behavior to the step change to a higher shear rate. The recovery time is dependent on the final shear rate specified, while the peak-stress viscosity decreases with increasing initial shear rate.

\section{DISCUSSION}

During the rest time, particle agglomeration and coarsening are more pronounced than when the sample is continuously sheared for the same amount of time. In the steadystate condition during stirring, a dynamic equilibrium exists in the steady-state condition where the agglomeration and deagglomeration processes both coexist.

All the step-change experiments are conditioned at a particular initial shear rate for a period of time ( $>30$ minutes) before changing the shear rate. The slurry would achieve a steady-state structure corresponding to the initial shear rate specified. There exists a dynamic equilibrium between the agglomeration and deagglomeration processes during the conditioning. Therefore, the particle structures are different from the step-change experiments that are left to rest initially. The coarsening process is dominant through the agglomeration between the particles when the slurry is left at rest. The steady constant shearing of the particles causes the particles to collide with each other, forming bonds, while at the same time breaking the join between the less-strongly bonded particles. In Figure 12, the peak stress recorded increases with decreasing initial shear rate. The results agree well with 
Table IV. Parameters Obtained from Step Change Experiments Using Equation [3] (Material: Sn15 Pct Pb Alloy Slurry, Fraction Solid at 0.36 and 0.50 (in Italics)

\begin{tabular}{|c|c|c|c|}
\hline $\begin{array}{c}\text { Shear Rate } \\
\text { Range } \\
\left(\mathrm{s}^{-1}\right)\end{array}$ & $\begin{array}{l}\text { Initial or Peak } \\
\text { Stress } \\
\text { Viscosity, } \eta_{p} \\
\text { (Pas)* }\end{array}$ & $\begin{array}{c}\text { Steady-State } \\
\text { Viscosity, } \\
\eta_{\text {s.s }}(\mathrm{Pas})^{* *}\end{array}$ & $\begin{array}{c}\text { Breakdown } \\
\text { Times } \tau \\
(\mathrm{s}) \dagger\end{array}$ \\
\hline 1 to 30 & 6.4 & 2.28 & 0.25 \\
\hline 1 to 50 & 3.1 & 1.08 & 0.22 \\
\hline 1 to 80 & 2.56 & 0.89 & 0.18 \\
\hline 1 to 100 & 2.47 & 0.82 & 0.16 \\
\hline 1 to 200 & 0.97 & 0.41 & 0.10 \\
\hline 10 to 100 & 2.2 & 0.79 & 0.16 \\
\hline 30 to 100 & 2.1 & 0.63 & 0.16 \\
\hline 50 to 100 & 0.8 & 0.50 & 0.16 \\
\hline 80 to 100 & 0.50 & 0.41 & 0.15 \\
\hline 50 to 200 & 0.77 & 0.25 & 0.09 \\
\hline 80 to 200 & 0.26 & 0.15 & 0.09 \\
\hline 100 to 200 & 0.18 & 0.14 & 0.25 \\
\hline 10 to 80 & 1.20 & 0.58 & 0.17 \\
\hline 30 to 80 & 1.00 & 0.54 & 0.17 \\
\hline 50 to 80 & 0.65 & 0.45 & 0.18 \\
\hline 30 to 80 & 8.3 & 1.5 & 0.19 \\
\hline 50 to 80 & 7.1 & 1.91 & 0.20 \\
\hline 50 to 200 & 2.30 & 1.21 & 0.12 \\
\hline 80 to 200 & 1.36 & 0.70 & 0.12 \\
\hline 100 to 200 & 0.68 & 0.43 & 0.11 \\
\hline 100 to 1 & 2.51 & 6.15 & 0.18 \\
\hline 100 to 10 & 0.93 & 1.45 & 0.20 \\
\hline 100 to 30 & 0.54 & 0.66 & 0.30 \\
\hline 100 to 50 & 0.44 & 0.52 & 0.40 \\
\hline 100 to 80 & 0.30 & 0.44 & 0.45 \\
\hline 10 to 1 & 14.89 & 26.66 & 0.18 \\
\hline 30 to 1 & 7.98 & 14.14 & 0.18 \\
\hline 50 to 1 & 3.4 & 7.95 & 0.19 \\
\hline 200 to 1 & 0.86 & 18.74 & 0.15 \\
\hline 50 to 10 & 1.27 & 2.05 & 0.22 \\
\hline 80 to 50 & 0.51 & 0.74 & 0.42 \\
\hline 30 to 10 & 1.76 & 3.24 & 0.25 \\
\hline 100 to 1 & 4.22 & 12.23 & 0.25 \\
\hline 100 to 10 & 1.11 & 2.13 & 0.50 \\
\hline 100 to 30 & 0.55 & 1.02 & 0.45 \\
\hline 100 to 50 & 0.52 & 0.87 & 0.52 \\
\hline 100 to 80 & 0.55 & 0.67 & 0.60 \\
\hline 10 to 1 & 15.00 & 35.1 & 0.30 \\
\hline 50 to 10 & 2.04 & 3.50 & 0.50 \\
\hline 50 to 30 & 1.09 & 2.04 & 0.35 \\
\hline 200 to 30 & 0.18 & 0.44 & 0.40 \\
\hline 80 to 50 & 0.75 & 1.13 & 0.55 \\
\hline
\end{tabular}

$*$ The errors are within 95 pct confidence limit $( \pm 0.5)$.

**The errors are within 95 pct confidence limit $( \pm 0.2)$

$\dagger$ The errors are within 95 pct confidence limit $( \pm 0.03)$.

works from other authors. ${ }^{[21,23]}$ At the low initial shear rate, the structure is more built up; therefore, a higher peak stress is recorded.

Kirkwood $^{[11]}$ suggested that at the high initial shear rate, the degree of deagglomeration is higher than that at the low initial shear rate. The result from Figure 12 agrees well with Quaak, ${ }^{[21]}$ who observed that a higher initial shear rate shows a lower viscosity compared to one done at a lower initial shear rate after a step change to the same final shear rate. The results obtained from this work agree with works by

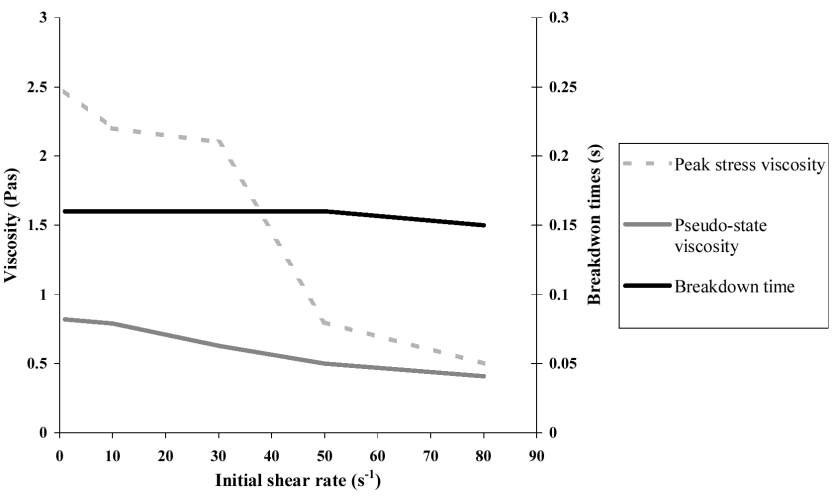

Fig. 13-Breakdown times, peak stress viscosity, and pseudostate viscosity during a step change to a final shear rate of $100 \mathrm{~s}^{-1}$ (material: Sn15 pct $\mathrm{Pb}$ alloy at $\left.F_{s}=0.36\right)$.

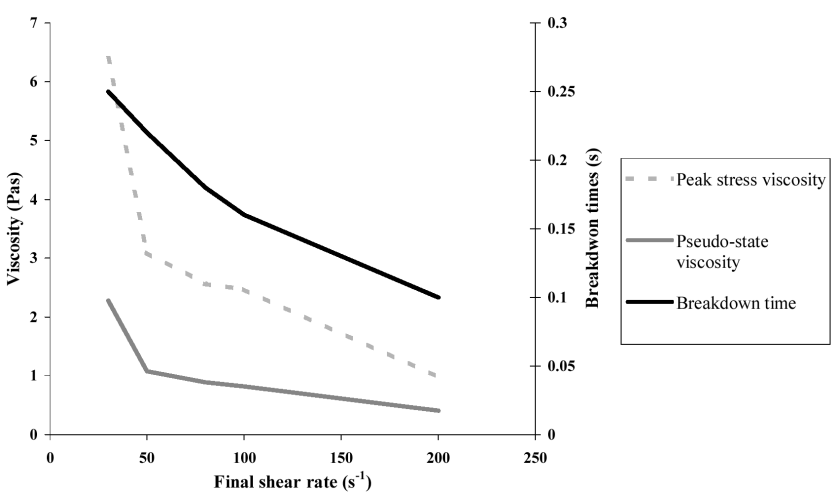

Fig. 14-Breakdown times, peak stress viscosity, and pseudostate viscosity during a step change from an initial shear rate of $1 \mathrm{~s}^{-1}$ (material: Sn15 pct $\mathrm{Pb}$ alloy at $\left.F_{s}=0.36\right)$.

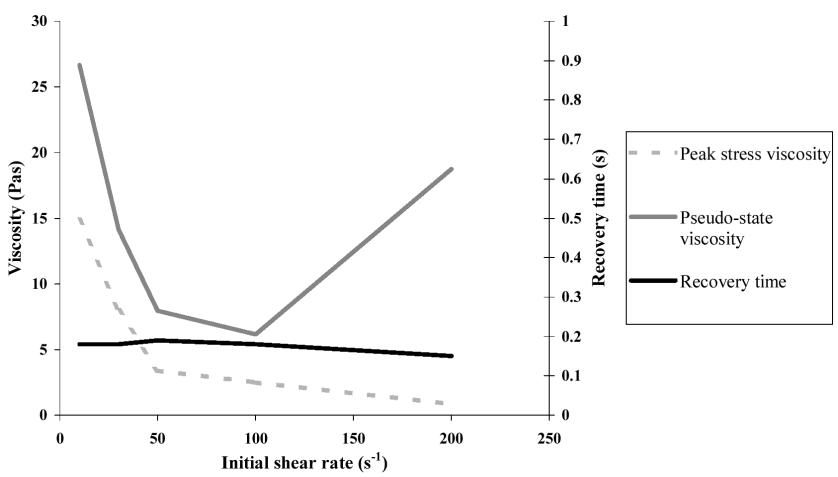

Fig. 15-Recovery times, peak stress viscosity, and pseudostate viscosity during a step change to a final shear rate of $1 \mathrm{~s}^{-1}$ (material: Sn15 pct $\mathrm{Pb}$ alloy at $\left.F_{s}=0.36\right)$.

other workers, ${ }^{[21,22,27-30]}$ who put forward the term "isostructure" during a shear-rate jump (i.e., the structure remains the same as the previous steady-state structure before decreasing or increasing with increasing or decreasing shear rates, respectively).

The "steady-state viscosity" in Table IV is also known as the "pseudostate viscosity" or the "first steady-state viscosity" after a step change in shear rate. It is not strictly a steady state. With increasing time at the constant shear rate, this viscosity will decrease or increase until it attains the 


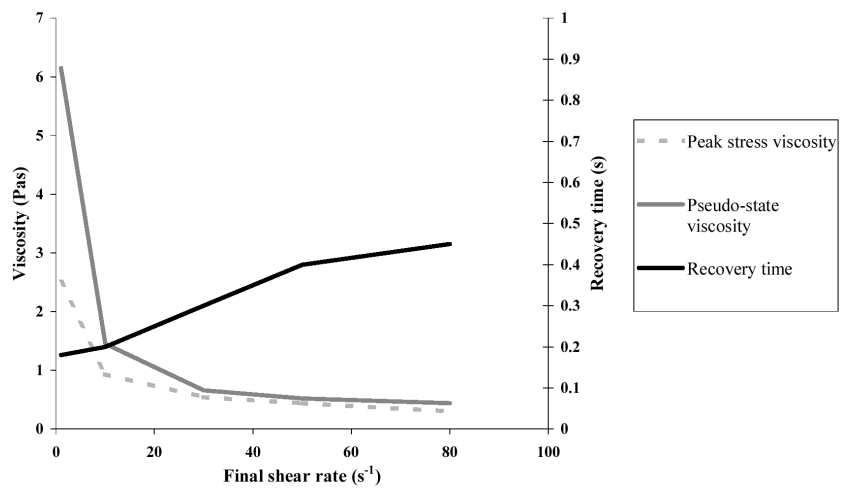

Fig. 16-Recovery times, peak stress viscosity, and pseudostate viscosity during a step change from an initial shear rate of $100 \mathrm{~s}^{-1}$ (material: Sn15 pet $\mathrm{Pb}$ alloy at $\left.F_{s}=0.36\right)$.

final steady-state viscosity corresponding to that shear rate. The breakdown times from the step-change experiments from an initial shear rate are affected by the final shear rate specified. Comparing Figures 13 and 14, it can be seen clearly that regardless of its initial shear rate, for the same final specified shear rate (Figure 13), the breakdown times remain almost constant. On the other hand (Figure 14), starting from the same initial shear rate, the breakdown times decrease with increasing final shear rate. Figure 14 also shows that the breakdown times decrease more rapidly in the lower-final-shear-rate region than in the higher-shearrate region.

This effect was also shown by Quaak ${ }^{[21]}$ and Koke and Modigell. ${ }^{[23]}$ However, the results obtained by Koke are collected over a long period of time $(\sim 10$ data points in 480 seconds). It was shown by Quaak that there exist two breakdown behaviors in semisolid slurries: a very fast (of the order of a few seconds) initial breakdown followed by a slower process (of the order of hundreds of seconds). Results from this work have shown that the very fast first breakdown process occurs within 1 second and, in this time, the metal slurry will have achieved its first pseudosteadystate condition. This is then followed by a second and longer breakdown ( $\sim 5$ minutes of constant shearing) before the material achieves its apparent steady-state condition corresponding to the specified shear rate. Koke's results are shown over a period of 480 seconds, and this can be regarded as the long-term behavior of the metal slurry after a change in shear rate.

To compare the recovery times with the breakdown times from the preceding section, step-change experiments to a lower shear rate from an initial high shear rate were conducted. Figure 15 showed the results for a step change to a final shear rate of $1 \mathrm{~s}^{-1}$ from five different initial shear rates. The initial viscosity before the step change at all five different initial shear rates showed similar results (again, in view of the experimental scatter) to that obtained from the steady-state experiments. The recovery times obtained from the fits to the stress-decay curves are shown to have similar behavior to the step-change experiments to a higher shear rate. The recovery time is shown to increase with increasing final shear rate, while remaining largely unaffected by the initial shear rate specified (Figure 16). One important finding in this experiment is that the recovery times obtained are slower than the breakdown times obtained for a shear-rate change to the same final shear rate (e.g., Table IV: shear rates from 1 to $50 \mathrm{~s}^{-1}$ and 100 to $50 \mathrm{~s}^{-1}$ ). For a step change to a lower shear rate, the structure initially consists of a more deagglomerated structure during shearing at the high initial shear rate. By reducing the shear rate, the time needed for the structure to agglomerate would be longer than that needed to break a well-structured state to a less-structured state. Quaak observed that the "breakdown" and "recovery" times are independent of the shear-rate-jump magnitude to the same final shear rate. The results obtained from this experiment (Figures 13 through 16) show that these times are, indeed, independent of the shear-rate-jump magnitude, but are largely dependent on the final shear rate specified.

The results from both the shear-rate jumps and drops show that these times are affected by the final shear rate specified, regardless of the initial shear rate. The results here agree with the behavior observed by Quaak. ${ }^{[21]}$ The work of Koke and Modigell, ${ }^{[23]}$ Mada and Ajersch, ${ }^{[27,28]}$ and Azzi et. al. ${ }^{[29]}$ also support the behavior of the slurry during a step change, as observed in this work.

\section{CONCLUSIONS}

1. The transient behavior of the slurry after a rapid change in shear rate is shown to occur within 1 second of the shear-rate jump. This is similar to an industrial thixoforming process. In the experiment conducted, it is shown that during a change in shear rate (in about 0.15 seconds), the semisolid structure would have broken down from its initial state.

2. A single exponential decay equation, described by a relaxation time, can be used to describe the initial rapid transient breakdown and/or recovery behavior of the semisolid slurries during a change in shear rate.

3. This initial breakdown (or relaxation) time is then described for a shear-rate jump from a lower shear rate to a higher shear rate. The first breakdown time is found to occur within the first second ( 0.1 to 0.25 seconds). This behavior is also seen in the recovery times for a shear-rate jump from a higher to a lower shear rate. The first recovery time is found to be longer than the breakdown times ( 0.18 to 0.45 seconds).

4. Microstructural examination of the semisolid slurries under different rest times shows that increasing rest times lead to an increase in agglomeration and particle sizes. These increases have contributed to the increase in shear stress recorded when the slurry is subjected to a change in shear rate from rest. The increase in particle sizes and degree of agglomeration would have impeded the movement of the particles sliding past each other, therefore increasing the shear stress recorded.

\section{ACKNOWLEDGMENTS}

The authors extend their thanks to Dr. P. Kapranos for his most useful suggestions. This work was carried out as part of EPSRC Grant No. GR/L/98473.

\section{REFERENCES}

1. D.B. Spencer, R. Mehrabian, and M.C. Flemings: Metall. Trans., 1972, vol. 3, pp. 1925-32. 
2. P.A. Joly and R. Mehrabian: J. Mater. Sci., 1976, vol. 11, pp. 13931418.

3. V. Laxmanan and M.C. Flemings: Metall. Trans. A, 1980, vol. 11, pp. 1927-36.

4. H.K. Moon, J.A. Cornie, and M.C. Flemings: Mater. Sci. Eng. A, 1991, vol. 144 , pp. $253-65$

5. T.Z. Kattamis and A.I. Nakhla: 2 nd Int. Conf. on Semi-Solid Processing of Alloys and Composites, Cambridge, MA, S.B. Brown and M.C. Flemings, eds., Massachusetts Institute of Technology Press, Cambridge, MA, 1992, pp. 237-47.

6. L.S. Turng and K.K. Wang: J. Mater. Sci., 1991, vol. 26, pp. 2173-83.

7. A.R.A. McLelland: Ph.D. Thesis, Sheffield University, Sheffield, United Kingdom, 1993.

8. P. Kumar, C.L. Martin, and S.B. Brown: Acta Metall. Mater., 1994, vol. 42, pp. 3595-3602.

9. C.J. Quaak, M.G. Horsten, and W.H. Kool: Mater. Sci. Eng. A, 1994, pp. 247-56.

10. M.C. Flemings: Metall. Trans. A, 1991, vol. 22A, pp. 957-79.

11. D.H. Kirkwood: Int. Mater. Rev., 1994, vol. 39, pp. 173-89.

12. P. Kapranos and K.P. Young: Mater. World, 1998, May, pp. 278-80.

13. K.P. Young and P. Eisen: 6th Int. Conf. on Semi-Solid Processing of Alloys and Composites, Turin, Italy, G.L. Chiarmetta and M. Rosso, eds., Edimet Spa, Brescia, Italy, 2000, pp. 97-102.

14. Z. Fan: Int. Mater. Rev., 2002, vol. 47(2), pp. 49-83.

15. P.J. Ward, H.V. Atkinson, and D.H. Kirkwood: 5th Int. Conf. on SemiSolid Processing of Alloys and Composites. CO, A.K. Bhasin, J.J. Moore, K.P. Young, and S. Midson, eds., Golden, Colorado, Colorado School of Mines, Golden, Colorado, USA, 1998, pp. 115-22.

16. P.J. Ward, H.V. Atkinson, D.H. Kirkwood, S.B. Chin, T.Y. Liu, and M.R. Barkhudarov: Modeling of Casting, Welding and Advanced Solidification Processes - IX, Shaker-Verlag, Aachen, Germany, 2000, P.R. Sahm, P.N. Hansen, and J.G. Conley, eds., 2000, pp. 397-403.
17. T.Y. Liu, P.J. Ward, D.H. Kirkwood, and H.V. Atkinson: XIIIth Int. Congr. on Rheology, Cambridge, United Kingdom, D.M. Binding, N.E. Hudson, J. Mewis, J.-M. Piau, C.J.S. Petrie, P. Townsend, M.H. Wagner, and K. Walters, British Society of Rheology, Glasgow, UK, 2000, vol. 4, pp. 61-63.

18. M.M. Cross: J. Coll. Sci., 1965, vol. 20, pp. 417-37.

19. Chambers Science and Technology Dictionary, Chambers, Edinburgh, 1994, p. 755.

20. P. Kumar: Ph.D. Thesis, Massachusetts Institute of Technology, Cambridge, MA, 1994.

21. C.J. Quaak: Ph.D. Thesis, Technische Univesiteit Delft, Delft, The Netherlands, 1996.

22. H. Peng and K.K. Wang: 4th Int. Conf. on Semi-Solid Processing of Alloys and Composites, Sheffield, United Kingdom, D.H. Kirkwood and P. Kapranos, eds., Dept. of Eng. Materials, University of Sheffield, Sheffield, UK, 1996, pp. 2-9.

23. J. Koke and M. Modigell: Proc. Int. Symp. on Advanced Forming and Die Manufacturing Technology, Haeundae-Pusan, Korea, C.G. Kang and Y.H. Moon, eds., Pusan National University, Pusan, Korea, 1999, pp. 101-106.

24. A.R.A. McLelland, N.G. Henderson, H.V. Atkinson, and D.H. Kirkwood: Mater. Sci. Eng. A, 1997, vol. 232, pp. 110-18.

25. J. Crank: Mathematics of Diffusion, Oxford University Press, London, 1964, p. 9.

26. F. Moore: Trans. Br. Ceram. Soc., 1959, vol. 58, pp. 470-94.

27. M. Mada and F. Ajersch: Mater. Sci. Eng. A, 1996, vol. 212, pp. 157-70.

28. M. Mada and F. Ajersch: Mater. Sci. Eng. A, 1996, vol. 212, pp. 17177.

29. L. Azzi, F. Ajersch, and T.F. Stephenson: 6th Int. Conf. on Semi-Solid Processing of Alloys and Composites, Turin, Italy, G.L. Chiarmetta and M. Rosso, eds., Edimet Spa, Brescia, Italy, 2000, pp. 527-32.

30. D. Brabazon: Ph.D. Thesis, University College Dublin, Dublin, 2001. 